\title{
Hepatite crônica B oculta: prevalência e aspectos clínicos em população de elevada endemicidade de infecção pelo vírus da hepatite B na Amazônia ocidental brasileira
}

\author{
Occult hepatitis B: prevalence and clinical characteristics in a population with \\ high endemicity of hepatitis B infection in the western Brazilian Amazon region
}

\author{
Gildo Maia Barros Júnior, ${ }^{1,2}$ Wornei Silva Miranda Braga ${ }^{1,2}$, Cintia Mara Costa de Oliveira ${ }^{1}$, \\ Márcia da Costa Castilhoo ${ }^{1,2}$ José de Ribamar Araújo ${ }^{1,2}$
}

\begin{abstract}
RESUMO
Recentemente é descrito estado de persistência do vírus da hepatite B denominado hepatite crônica B oculta. Sua prevalência e fisiopatologia são desconhecidas. 0 objetivo deste estudo foi avaliar a ocorrência dessa entidade clínica em pacientes da Amazônia brasileira. De 51 pacientes anti-HBc total reativos testados pela reação em cadeia da polimerase, $17 \%$ foram positivos. Não observamos associação com fatores de risco clássicos de infecção pelo vírus da hepatite B, testes bioquímicos, hematológicos e histopatologia. No entanto, os pacientes ictéricos e reativos para o anti-HIV apresentaram associação com a presença do ADN-vírus da hepatite B. Os resultados demonstram a ocorrência da hepatite crônica B oculta, entre nossos doentes, porém, com taxas de prevalência abaixo do esperado para a região. Acreditamos que, apesar do tamanho da amostra avaliada ser pequeno, sua ocorrência poderia ter sido maior se empregássemos primers para a região $\mathrm{S}, \mathrm{C}$ e X do genoma do vírus da hepatite $\mathrm{B}$, aumentando a sensibilidade do teste.
\end{abstract}

Palavras-chaves: Hepatite B oculta. ADN-vírus da hepatite B. Hepatite crônica. Amazônia Ocidental Brasileira.

\begin{abstract}
A persistent form of the hepatitis B virus called occult chronic hepatitis B has recently been described. Its prevalence and physiopathology are unknown. The aim of this study was to evaluate the occurrence of this clinical entity among patients in the Brazilian Amazon region. Out of 51 anti-HBc totalpositive patients who were tested using the polymerase chain reaction, $17 \%$ were positive. We did not find any associations with classical risk factors for hepatitis B virus infection or with biochemical tests, hematological tests or histological patterns. However, the jaundiced and HIV-positive patients showed a statistical association with the presence of hepatitis B virus-DNA. The results demonstrated that occult hepatitis B occurred among our patients, but at prevalence rates lower than expected for this region. We believe that despite the small sample size, the occurrence might have been found to be greater if we had used primers for the S, C and X regions of the hepatitis B virus genome, thereby increasing the sensitivity of the test.
\end{abstract}

Key-words: Occult hepatitis B. Hepatitis B virus-DNA. Chronic hepatitis. Brazilian Amazon region.

Estima-se que aproximadamente $1 / 3$ da população mundial já teve contato com o vírus da hepatite B (VHB) e que cerca de 350 milhões de pessoas apresentam infecção ativa, portadoras do antígeno de superfície do VHB (AgHBs) ${ }^{31}$.

0 vírus da hepatite $B$ não é um vírus diretamente citopático. A evolução da doença dependerá da resposta imune do hospedeiro, pois tanto o componente celular quanto o humoral são necessários para a eliminação do vírus, principalmente, a ação de linfócitos T citotóxicos $\left(\mathrm{CD}_{8}^{+}\right)$dirigidos contra antígenos do core viral ${ }^{17}$.

0 vírus da hepatite $B$ determina uma ampla variedade de apresentações clínicas, de portador assintomático a manifestações graves como hepatite fulminante, hepatite crônica, cirrose e carcinoma hepatocelular (CHC) ${ }^{17}$.

O desenvolvimento da biologia molecular e um melhor conhecimento da variabilidade genética do VHB conduziram a uma revisão dos padrões sorológicos da infecção. 0 AgHBs era considerado o marcador de infecção ativa, e o anti-HBc só indicaria infecção prévia. Porém, foi demonstrado que pacientes que receberam transfusão sanguínea positivas para o anti-HBc, sendo negativos para 0 AgHBs e anti-HBs, resultaram em infecção pelo $\mathrm{VHB}^{26}$.

Atualmente, classificam-se os estados de persistência viral baseando-se em achados sorológicos: hepatite B crônica, portador

\footnotetext{
1. Fundação de Medicina Tropical do Amazonas, Manaus, AM. 2. Universidade do Estado do Amazonas, Manaus, AM.

Endereço para correspondência: Dr. Gildo Maia de Barros Júnior. Gerência de Virologia/FMT-AM. Av. Pedro Teixeira 25, 69040-000 Manaus, AM.

Telefax: 5592 3238-3762

e-mail: gildo.maia@bol.com.br

Recebido para publicação em 29/10/2007

Aceito em 14/10/2008
} 
inativo e hepatite B oculta ${ }^{27}$. A hepatite B oculta é definida como a detecção do ADN do VHB no soro ou no tecido hepático de pacientes negativos para $0 \mathrm{AgHBs}^{15}$, geralmente com carga viral em torno de $10^{2-3}$ cópias $/ \mathrm{ml}$ no soro ${ }^{29}$. Algumas pesquisas ainda questionam a existência da hepatite B oculta e suas implicações clínicas. Porém, existem evidências científicas que comprovam que a hepatite $\mathrm{B}$ oculta é uma entidade clínica genuína ${ }^{1024}$.

Não obstante, a hepatite B oculta tem sido implicada como causa de doença hepática crônica idiopática ${ }^{13}$. Na França foi demonstrada positividade para o ADN do VHB em 30\% de pacientes com hepatite crônica criptogênica ${ }^{14}$.

Por outro lado, outros estudos com técnicas imunohistoquímicas, apesar da positividade para marcadores em indivíduos AgHBs negativos/ADN-VHB positivos, o nível de expressão destas proteínas foi baixo, sugerindo contribuição de outros fatores associados: VHC, HIV e etilismo crônico ${ }^{21}$.

Apesar de sua importância clínica potencial, a prevalência da infecção oculta pelo VHB ainda é desconhecida ${ }^{1122}$. Várias investigações mostraram que 30 a 35\% de indivíduos AgHBs negativos portadores de hepatite crônica com ou sem $\mathrm{CHC}$, tenham soropositividade para o $\mathrm{ADN}$ do $\mathrm{VHB}^{614}$.

A região Amazônica é caracterizada como uma das regiões do mundo de maior ocorrência da doença e suas consequiências ${ }^{7}$. No Estado do Amazonas, as calhas dos Rios Juruá, Purus e médio Solimões são consideradas as regiões de maior endemicidade, com taxas significativamente elevadas ${ }^{58}$.

Em nossa região não dispomos de estudos relativos a essa nova entidade clínica. Assim, faz-se de grande necessidade 0 conhecimento da prevalência da hepatite B oculta em nosso meio, da presença de co-infecção com outros vírus e de fatores correlatos caracterizando até que ponto as hepatites crônicas criptogênicas possam corresponder à hepatite crônica B oculta, para melhor compreender o seu papel patogênico e suas repercussões clinicas.

\section{MATERIAL E MÉTODOS}

Trata-se de um estudo descritivo de uma série de casos, de caráter prospectivo de pacientes incluídos com base em critério diagnóstico de hepatite crônica de etiologia desconhecida, selecionados a partir de banco de dados do ambulatório especializado de hepatites virais, da Fundação de Medicina Tropical do Amazonas no período de julho de 2004 a agosto de 2006. 0 protocolo de estudo foi aprovado pelo Comitê de Ética da Fundação de Medicina Tropical do Amazonas (2882/2003 FMT/IMT-AM).

Os pacientes foram incluídos de acordo com os seguintes critérios: soropositividade para o anti-HBc total e não reativos para o AgHBs; presença de sinais e/ou sintomas de doença hepática crônica sem etiologia definida; elevação de aminotransferases com AST acima de 37U/L, e ALT acima de 65U/L, em pelo menos 2 aferições, por um período superior a seis meses; pacientes com hepatite $\mathrm{C}$ crônica e os HIV positivos (que não estivessem usando antiretrovirais), apresentando soropositividade para o anti-HBc total e não reativos para o AgHBs, também foram incluídos no estudo. Os pacientes etilistas crônicos, diabéticos, portadores de insuficiência cardíaca congestiva, neoplasias, tuberculose, doença pulmonar obstrutiva crônica, AIDS e em uso de drogas potencialmente hepatotóxicas foram excluídos por apresentarem risco em potencial de doença hepática de outra natureza que não viral.

Os pacientes com sorologia positiva para o anti-HBc total e negativos para o AgHBs, foram selecionados do banco de dados da Gerência de Virologia da Fundação de Medicina Tropical do Amazonas, no período de julho de 1997 a dezembro de 2003. Após busca no banco de dados, os prontuários foram resgatados do Núcleo de Arquivamento Médico e Estatística (NAME-FMTAM) quando foram aplicados os critérios de inclusão e exclusão para serem convidados a participar do estudo por contato telefônico, envio de cartas ou visita aos domicílios.

Os indivíduos encaminhados ao ambulatório, a partir do início do estudo, e que preenchiam os critérios de inclusão foram convidados a participar durante as primeiras consultas. Posteriormente, os seguintes passos foram tomados: implantação do ambulatório especializado; apresentação do termo de consentimento livre e esclarecido; entrevista para aplicação do questionário e exame físico; coleta de amostra de sangue para novos testes sorológicos, hematológicos, bioquímicos e biologia molecular.

A contagem de plaquetas e o hemograma completo foram realizados, através do sistema automatizado, com aparelho Coulter ${ }^{\circledR}$. coagulograma (tempo de protrombina realizados pelo sistema Behring Fibrintiner II $\left.{ }^{\circledR}\right)$. Foram realizadas as seguintes dosagens bioquímicas: glicose, uréia, creatinina, proteína total, globulina, albumina, bilirrubina total, bilirrubina direta, bilirrubina indireta, Aspartato aminotransferase, alanina aminotrasferase, gama-glutamil transpeptidase, fosfatase alcalina, por meio do sistema automatizado, com aparelho da marca Dade- Behring ${ }^{\circledR}$.

Os testes sorológicos para os vírus da hepatite B, C, Delta e HIV (vírus da imunodeficiência humana), foram realizados por método imunoenzimático (ELISA): o AgHBs, anti-HBc total, o anti$\mathrm{HBe}, \mathrm{AgHBe}$, anti-HBs, anti-HCV, anti-HD total e anti-HIV1/2, com Kits comerciais (DiaSorin, S.p.A. - Saluggia, Italy), executados e interpretados conforme as indicações do fabricante.

A extração do ADN do VHB foi realizada utilizando Kit comercial QIAgen ${ }^{\circledR}$ mini Kit, conforme as recomendações do fabricante. A detecção do ADN-VHB foi realizada por reação em cadeia da polimerase (PCR), utilizando o sistema semi-nested PCR. Os primers externos utilizados na primeira reação foram 2.128 (5'-GGGTCACCATATTCTTGG-3') e 783 (5'-CTCACGATGCTGTACAGA-3'). Na segunda reação, utilizou-se os primers P1 (5'-CTCACGATGCTGTACAGA-3') e 783. 0 produto da PCR obtido, após a segunda reação, correspondeu a 680pb (pares de bases). Todas as amostras foram testadas pelo menos duas vezes desde a extração, até a amplificação do gene $S$. Os pacientes anti-VHC positivos, foram submetidos a PCR para identificação do ARN do VHC. 
As biópsias hepáticas foram realizadas após assinatura do consentimento informado, naqueles pacientes em condições clínicas. A via de coleta foi a percutânea intercostal transpleural, não guiada por ultra-sonografia, usando agulha de Menghini (aspiração) ${ }^{16}$ e as alterações histopatológicas foram analisadas de acordo com as classificações de METAVIR .

Os dados foram registrados em um banco de dados (Excel 2003), e as análises estatísticas foram conduzidas utilizando-se o programa Epi-Info ${ }^{12}$. A análise dos dados foi iniciada com descrição estatística simples, intervalo de confiança (IC 95\%) e testes de significância empregados para validar essas proporções encontradas. Foram calculadas médias, IC 95\% e testes de significância para variáveis numéricas. A presença de exposição a fatores de risco foi dicotomizada em presente e ausente, para determinar se existia associação entre a exposição ao fator e a ocorrência do marcador avaliado, medindo-se a associação através do cálculo das razões de prevalência (RP).

\section{RESULTADOS}

Foram selecionados 24 pacientes retrospectivamente e 28 durante o desenvolvimento do estudo, com diagnóstico de hepatite crônica e sorologia positiva para o anti-HBc total e negativos para 0 AgHBs, totalizando 52 pacientes. A Tabela 1 mostra a distribuição da presença de fatores de risco clássicos de infecção pelo VHB.

Os pacientes foram avaliados periodicamente, por um período mínimo de seis meses, dependendo da data da inclusão, e com intervalo mínimo de dois meses, foram realizados os testes bioquímicos e hematológicos, que estão resumidos na Tabela 2.

Tabela 1 - Distribuição quanto à presença de fatores de risco de infecção pelo VHB entre os pacientes avaliados.

\begin{tabular}{llr}
\hline & \multicolumn{2}{c}{ Pacientes } \\
\cline { 2 - 3 } Fatores de risco & $\mathrm{n}^{0}$ & $\%$ \\
\hline Doenças sexualmente transmissíveis & 22 & 42,3 \\
Relato de hepatite & 17 & 32,7 \\
Relato de hepatite na família & 32 & 61,5 \\
Antecedente de cirurgia & 27 & 51,9 \\
Transfusão sanguínea ou derivados & 12 & 23,1 \\
\hline
\end{tabular}

Tabela 2 - Valores médios dos principais marcadores bioquímicos e bematológicos avaliados.

\begin{tabular}{lrrrrc}
\hline Exames & Média & Mínimo & Máximo & Mediana & Desvio padrão \\
\hline ALT (U/L) & 105,70 & 42,30 & 429,30 & 84,40 & 71,30 \\
AST (U/L) & 78,70 & 12,00 & 447,00 & 52,00 & 80,20 \\
GGT (U/L) & 191,20 & 20,50 & 1170,00 & 132,50 & 209,80 \\
FA (U/L) & 146,20 & 55,70 & 476,50 & 109,00 & 97,20 \\
BT (mg/dL) & 1,48 & 0,34 & 8,08 & 1,11 & 1,62 \\
Albumina (g/dL) & 3,44 & 0,90 & 4,70 & 3,80 & 0,92 \\
Hematócrito (\%) & 38,10 & 28,30 & 46,00 & 38,70 & 4,81 \\
Plaquetas $\left(103 / \mathrm{mm}^{3}\right)$ & 189,10 & 29,00 & 338,00 & 193,50 & 81,80 \\
\hline
\end{tabular}

ALT: alanino amotransferase, AST: aspartato aminotransferase, GGT: gamaglutamiltransferase, FA: fosfatase alcalina; BT: bilirrubinas totais, U/L: unidade por litro, mg/dL: miligrama por decilitro, $\mathrm{g} / \mathrm{dL}$ : grama por decilitro, \%: porcentagem, $\mathrm{mm}^{3}$ : milímetro cúbico.
Dez (19,2\%) foram positivos para o anti-HCV e todos com infecção confirmada pela PCR. Cinqüenta e um dos pacientes acompanhados realizaram teste para $0 \mathrm{ADN}-\mathrm{VHB}$ pela reação da PCR, nove (17,6\% IC 95\% 8,4\%-30,9\%) apresentaram reatividade (Figura 1).

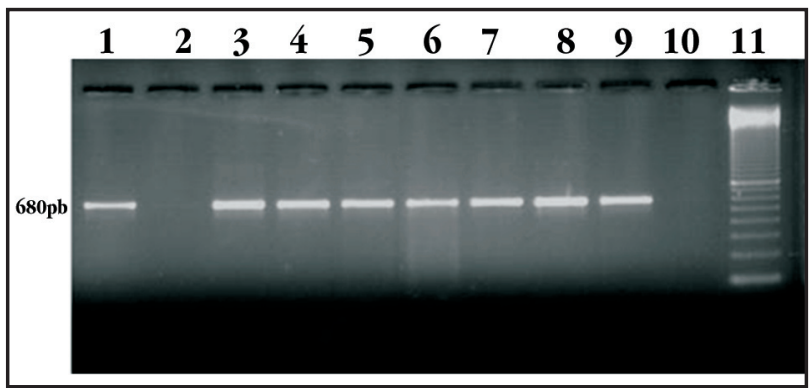

Figura 1 - Perfil eletroforético, em gel de agarose, dos produtos amplificados pela PCR em sete das nove amostras positivas: coluna 1: controle positivo, colunas 2 e 10: controle negativo, colunas de 3 a 9: amostras positivas, coluna 11: marcador ADN $100 p b$.

Observamos alguns padrões atípicos de perfil sorológico, entre os pacientes acompanhados. Em nenhum dos dez pacientes anti-HCV reativos foi detectado o ADN-VHB pela PCR, nem entre os quatro anti-HD total.

Dos 52 testados, 28 (56\%) foram positivos para o anti-HBe, nenhum foi positivo para o AgHBe, $31(60,8 \%)$ apresentava 0 anti-HBs, 5 (16,7\%) entre os ADN-VHB reativos. Três (6\%) apresentaram positividade para o HIV (Tabela 3 ).

Tabela 3 - Perfil sorológicos dos pacientes incluídos no estudo.

\begin{tabular}{lrr}
\hline & \multicolumn{2}{c}{ Pacientes } \\
\cline { 2 - 3 } Marcador sorológico & $\mathrm{n}^{0}$ & $\%$ \\
\hline Anti-HIV 1/2 & 3 & 6,0 \\
Anti-HBs & 31 & 60,8 \\
AgHBs negativo & 52 & 100,0 \\
Anti-HBc T & 52 & 100,0 \\
Anti-HBe & 28 & 56,0 \\
Anti-HCV & 10 & 19,2 \\
Anti-HD T & 4 & 8,0 \\
\hline
\end{tabular}

Anti-HIV: anticorpo contra o HIV 1/2, anti-HBs: anticorpo contra antígeno de superfície do VHB, AgHBs: antígeno de superfície do VHB, anti-HBc T: anticorpo contra o antígeno core do VHB, anti-HBe: anticorpo contra o antígeno "e" do VHB, anti-HCV: anticorpo contra o VHC, anti-HD T: anticorpo contra o VHD.

Foi possível realizar 17 biópsias hepáticas. Três pacientes apresentaram esteatohepatite, dois não apresentavam atividade histológica e um teve diagnóstico de hepatite crônica leve. Oito pacientes não apresentaram atividade histológica. Três pacientes apresentaram diagnóstico de hepatite crônica leve, três pacientes com diagnóstico de hepatite crônica moderada e três hepatite crônica intensa a cirrose. Em 17 pacientes biopsiados, o ADN do VHB foi identificado em três: um apresentou diagnóstico de cirrose hepática, outro hepatite crônica moderada e um sem atividade histológica.

A positividade do ADN-VHB pela PCR foi avaliada quanto à presença de fatores de risco clássicos de infecção pelo VHB, aspectos clínicos, perfil histológico, bioquímico, hematológico e 
sorológico. Observamos associação estatisticamente significativa com a presença de reatividade para o HIV ( $\mathrm{RP}=4,38 \mathrm{IC} 95 \%, 1,53-12,53$, $\mathrm{p}=0,02$, teste exato de Fisher) e presença de icterícia ( $\mathrm{RP}=4,6 \mathrm{IC} 95 \%$ $1,63-12,93, \mathrm{p}=0,03$, teste exato de Fisher) (Tabela 4).

Não observamos associação estatisticamente significativa entre a detecção do ADN-VHB, idade, história de cirurgia ou transfusão de sangue ou derivados, etilismo social, descompensação da doença e resultado do exame histopatológico.

Os pacientes ADN-VHB reativos, em media apresentam hematócrito mais baixo, níveis séricos de ALT, AST e GGT mais elevados e albumina mais baixa, embora não tenham sido observadas diferenças estatisticamente significativas (Tabela 5).

\begin{tabular}{lccccc}
$\begin{array}{l}\text { Tabela } 4 \text { - Fatores } \\
\text { avaliados. }\end{array}$ & \multicolumn{5}{l}{} \\
\hline Variável & Número & Prevalência & RP & IC95\% & p \\
\hline Gênero & & & & & \\
$\quad$ feminino & $5 / 21$ & 23,8 & 1,78 & $0,54-5,87$ & 0,37 \\
$\quad$ masculino & $4 / 30$ & 13,3 & & & \\
Icterícia & & & & & \\
$\quad$ sim & $3 / 5$ & 60,0 & 4,61 & $1,63-12,93$ & 0,03 \\
$\quad$ não & $6 / 46$ & 13,0 & & & \\
Esplenomegalia & & & & & \\
$\quad$ sim & $3 / 17$ & 17,6 & 1,00 & $0,28-3,51$ & 0,64 \\
$\quad$ não & $6 / 34$ & 17,6 & & & \\
Hepatite na família & & & & & \\
sim & $7 / 32$ & 21,9 & 2,07 & $0,48-8,99$ & 0,26 \\
$\quad$ não & $2 / 19$ & 10,5 & & & \\
Anti-HIV 1/2 & & & & & \\
$\quad$ positivo & $2 / 3$ & 66,7 & 4,38 & $1,53-12,53$ & 0,02 \\
negativo & $7 / 46$ & 15,2 & & & \\
\hline
\end{tabular}

Anti-HIV 1/2: anticorpo contra o HIV 1/2, RP: razão de prevalência, IC95\%: intervalo de confiança, p: significância estatística.

Tabela 5 - Associação da presença do ADN-VHB e parâmetros bioquímicos e bematológicos, nos pacientes avaliados.

\begin{tabular}{|c|c|c|c|}
\hline Parâmetro & Número & Média & $\mathrm{p}$ \\
\hline \multicolumn{4}{|l|}{$\overline{\text { ALT }}$} \\
\hline PCR positivo & 9 & 124,00 & 0,33 \\
\hline PCR negativo & 42 & 98,80 & \\
\hline \multicolumn{4}{|l|}{ AST } \\
\hline PCR positivo & 9 & 125,30 & 0,11 \\
\hline PCR negativo & 42 & 64,50 & \\
\hline \multicolumn{4}{|l|}{ GGT } \\
\hline PCR positivo & 9 & 268,70 & 0,20 \\
\hline PCR negativo & 42 & 170,20 & \\
\hline \multicolumn{4}{|l|}{ Hematócrito } \\
\hline PCR positivo & 9 & 36,00 & 0,12 \\
\hline PCR negativo & 42 & 38,00 & \\
\hline \multicolumn{4}{|l|}{ Plaquetas } \\
\hline PCR positivo & 9 & 204,00 & 0,55 \\
\hline PCR negativo & 42 & 185,00 & \\
\hline \multicolumn{4}{|l|}{ Bilirubinas totais } \\
\hline PCR positivo & 9 & 2,23 & 0,13 \\
\hline PCR negativo & 42 & 1,32 & \\
\hline
\end{tabular}

ALT: alanino aminotransferase (U/L), AST: aspartato aminotransferase, GGT: gamaglutamiltransferase (U/L), PCR: reação em cadeia da polimerase, hematócrito (\%), plaquetas $\left(103 / \mathrm{mm}^{3}\right)$, bilirrubinas totais $(\mathrm{mg} / \mathrm{dL})$, p: significância estatística.

\section{DISCUSSÃo}

A presença do anti-HBc no soro, com AgHBs negativo, pode indicar infecção prévia resolvida ou estado de portador do $\mathrm{VHB}^{19}$, e existem evidências crescentes que pacientes com esse perfil sorológico podem também desenvolver doença hepática crônica ou transmitir a doença para outros indivíduos ${ }^{128}$.

Conduzimos um estudo em indivíduos com sorologia reativa para o anti-HBc total isolado com sinais e sintomas de hepatite crônica, investigando a presença do ADN do VHB em amostras de sangue de 51 pacientes com esse perfil.

Das 51 amostras submetidas à reação da PCR, nove $(17,6 \%$ IC 95\% 8,4\%-30,9\%) revelaram-se positivas para o ADN-VHB. A prevalência encontrada neste estudo, não difere dos resultados encontrados em estudos semelhantes onde são relatadas taxas entre 11 e $19 \%{ }^{10}$.

Entretanto, esta taxa mostrou-se inferior a observada em outras regiões onde a hepatite B é endêmica, como a encontrada em países asiáticos, principalmente na China, com relatos de positividade para o ADN do VHB em amostras do sangue de 35,2\% pacientes atendidos na cidade de Hainan. Todos os pacientes foram definidos como crônicos assintomáticos e apresentavam o anti-HBc como o único marcador de infecção passada pelo $\mathrm{VHB}^{18}$.

Em outro estudo Chinês na Cidade de Tongii, em 84 pacientes AgHBs negativos, porém com marcadores de infecção pregressa e doença hepática crônica, foi encontrado positividade para o ADN do VHB no plasma em 25 pacientes revelando uma prevalência de $30 \%^{30}$.

Em Hong Kong, estudo utilizando primers para a região $S$ do genoma do $\mathrm{VHB}$, foi pesquisado a presença do $\mathrm{ADN}$ do $\mathrm{VHB}$ no soro de três grupos populacionais, grupo I cirrose criptogênica, grupo II sem doença hepática e grupo III pacientes com cirrose pelo VHB. Em 32\% do grupo I, encontrou positividade para o ADN do VHB, nenhum paciente do grupo II foi positivo e finalmente $54 \%$ do grupo III apresentou positividade para o $\mathrm{ADN}$ do $\mathrm{VHB}^{13}$.

$\mathrm{Na}$ Espanha, onde a prevalência da hepatite B é considerada moderada $a^{6}$, foi identificada a presença do ADN do VHB em 18,8\% de pacientes com diagnóstico de hepatite crônica criptogênica ${ }^{6}$. Entretanto, na França, onde a endemicidade é baixa, em um estudo de prevalência de hepatite $B$ oculta, em pacientes com hepatite crônica de causa desconhecida, foi encontrada uma prevalência de $30 \%$, sendo confirmada a presença do ADN do VHB no tecido hepático dos mesmos pacientes ${ }^{14}$.

No Brasil, na Cidade de Porto Alegre, em estudo da prevalência da infecção oculta pelo VHB em pacientes infectados com o VHC e portadores de carcinoma hepatocelular, não foi encontrada a presença do ADN do VHB em amostras de soro, na população estudada ${ }^{2}$.

Considera-se então, que em populações altamente expostas ao VHB, ou seja, procedentes de áreas com elevada endemicidade, a prevalência esperada de hepatite $B$ oculta seria maior ${ }^{13}$

A prevalência encontrada de hepatite crônica B oculta em nosso estudo está abaixo da encontrada em regiões onde a prevalência do VHB é superior a $8 \%$. 
Uma provável explicação para este fato, seria que a maioria dos pacientes avaliados tinha doença hepática crônica de leve a moderada (65\%) e o restante (35\%) elevação de transaminases sem evidencias histológicas de hepatite crônica, em que a média de ALT não chega a duas vezes o limite superior de normalidade, com provável baixa carga viral do $\mathrm{VHB}$, teria influenciado a sensibilidade na PCR.

Outra explicação da baixa prevalência encontrada pudesse ser pelo fato de apenas ter sido utilizada a região $S$ do genoma do VHB como região alvo para a PCR, enquanto em outros estudos foram empregadas também outras regiões do genoma do vírus, como por exemplo, a região do Core, a região $\mathrm{X}$ e da polimerase $\mathrm{e}^{1015}$.

Ainda, com relação às técnicas biomoleculares empregadas, o fragmento amplificado pela PCR no presente estudo foi 600 pares de bases, enquanto o recomendado para o diagnóstico são fragmentos menores, em média de 200 a 400 pares de bases, 0 que aumentaria a sensibilidade do teste ${ }^{14}$.

Em nosso estudo, não observamos associação significativa entre a presença de hepatite crônica $B$ oculta e fatores de risco clássicos de infecção pelo VHB, coincidindo com dados da literatura ${ }^{2027}$.

Apesar da amostra ter sido pequena, os pacientes com icterícia apresentaram um risco quatro vezes maior de positividade para o ADN-VHB. A icterícia é um sinal de complicação e representa doença hepática ativa e prognóstico reservado ${ }^{25}$. Este fato é relevante, pois em trabalhos envolvendo grupos em diferentes estágios de doença hepática, a prevalência do ADN-VHB foi maior naqueles com doença hepática avançada ${ }^{611}$.

Os pacientes avaliados eram doentes crônicos em diferentes estágios de evolução. Dos três pacientes com icterícia, dois apresentavam cirrose descompensada e um hepatite crônica de intensa atividade, diagnosticada por exame histopatológico.

Os pacientes anti-HIV positivos apresentaram um risco quatro vezes quatro vezes maior de positividade para $0 \mathrm{ADN}-\mathrm{VHB}$, sugerindo associação entre a positividade para 0 HIV e hepatite crônica B oculta em nosso estudo.

Em áreas endêmicas estima-se que aproximadamente 90\% dos pacientes portadores do HIV tenham marcadores sorológicos de infecção pregressa pelo VHB e que destes, pelo menos 10\% a $15 \%$ sejam portadores crônicos do $\mathrm{VHB}^{23}$.

Com relação aos pacientes com hepatite C, nenhum foi positivo para o ADN-VHB. Acredita-se que os mecanismos de transmissão da hepatite B e C não sejam os mesmos em nossa região, pois a transmissão do VHB ocorre principalmente na infância, de mãe para filho (perinatal) ou horizontalmente dentro da mesma familia ${ }^{3}$, e 0 VHC é predominantemente transmitido por via parenteral ${ }^{9}$.

Por outro lado, uma das razões para a não detecção do ADN-VHB nos pacientes portadores de hepatite $\mathrm{C}$, pode ser também relacionada à baixa carga viral do $\mathrm{VHB}$ e à sensibilidade do teste.

0 presente estudo foi capaz de detectar a presença de hepatite crônica B oculta, na Amazônia ocidental brasileira, associando sua presença com passado de icterícia e presença de reatividade para o HIV.

\section{AGRADECIMENTOS}

Agradecemos à Fundação de Medicina Tropical do Amazonas (FMT-AM), Universidade do Estado do Amazonas (UEA), Superintendência da Zona Franca de Manaus (SUFRAMA), Fundação de Amparo à Pesquisa do Estado do Amazonas (FAPEAM).

\section{REFERÊNCIAS}

1. Allain JP. Occult hepatitis B virus infection. Transfusion Clinique et Biologique 11:18-25, 2004

2. Araújo FSB. Diagnóstico da Infecção oculta pelo virus da hepatite B em pacientes com hepatopatia crônica pelo vírus C. Porto Alegre: FFPA. Dissertação de Mestrado, Fundação Faculdade de Ciências Médicas de Porto Alegre, Porto Alegre, RS, 2004.

3. Azevedo RA, Silva AE, Ferraz ML, Marcopolino LF, Baruzzi RG. Prevalência dos marcadores sorológicos dos vírus da hepatite $\mathrm{B}$ e $\mathrm{D}$ em crianças das tribos Caiabi e Txucarramãe do Parque Indígena do Xingu, Brasil Central. Revista da Sociedade Brasileira de Medicina Tropical 29:431-439, 1996.

4. Bedossa P, Poynard T. An algorithm for the grading of activity in chronic hepatitis C. The METAVIR Cooperative Study Group. Hepatology 24:289-293, 1996.

5. Bensabath G, Leão RNQ. Prevalência na Amazônia Brasileira. In: Focaccia R (ed) Tratado de Hepatites Virais, 2a edição, Atheneu, São Paulo, p.11-26, 2007.

6. Berasain C, Betés M, Panizo A, Ruiz J, Herrero JI, Civeira MP, Prieto J. Pathological and virological findings in patients with persistent hypertransaminasaemia of unknown aetiology. Gut 47:429-435, 2000.

7. Braga WS, Brasil LM, Souza RA, Castilho MC, Fonseca JCF. Ocorrência da infecção pelo vírus da hepatite B (VHB) e delta (VHD) em sete grupos indígenas do Estado do Amazonas. Revista da Sociedade Brasileira de Medicina Tropical 34:349-355, 2001.

8. Braga WS, Silva EB, Souza RA, Tosta CE. Soroprevalência da infecção pelo vírus da hepatite B e pelo plasmódio em Lábrea, Amazonas: estimativa da ocorrência de prováveis coinfecções. Revista da Sociedade Brasileira de Medicina Tropical 38:218-223, 2005.

9. Brasil LM, Braga WS, Fonseca JCF, Souza RA. Fatores de risco na transmissão do vírus da hepatite C (HCV) na Amazônia Ocidental. Revista da Sociedade Brasileira de Medicina Tropical 31 (supl I):87, 1998.

10. Bréchot C, Thiers V, Kremsdorf D, Nalpas B, Pol S, Paterlini-Bréchot P. Persistent hepatitis $B$ virus infection in subjects without hepatitis B surface antigen: clinically significant or purely "occult”? Hepatology 34:194-203, 2001.

11. Cacciola I, Pollicino T, Squadrito G, Cerenzia G, Orlando ME, Raimondo G. Occult hepatitis $B$ virus infection in patients with chronic hepatitis $\mathrm{C}$ liver disease. New England Journal of Medicine 341:22-26, 1999.

12. Center Disease Central. Epi Info ${ }^{\mathrm{TM}}$ statistical software, version 3.3.2, CDC; Atlanta GA, 2005.

13. Chan HL, Tsang SW, Leung NW, Tse CH, Hui Y, Tan JS, Chan FK, Sung JJ. Occult $\mathrm{HBV}$ infection in cryptogenic liver cirrhosis in an area with high prevalence of HBV infection. American Journal of Gastroenterology 97:1211-1215, 2002.

14. Chemin I, Zoulim F, Merle P, Arkhis A, Chevallier M, Kay L, Cova L, Chevallier P, Mandrand B, Trépo C. High incidence of hepatitis B infections among chronic hepatitis cases of unknown aetiology. Journal of Hepatology 34:447-454, 2001.

15. Conjeevaram HS, Lok AS. Occult hepatitis B virus infection: a hidden menace? Hepatology 34:204-206, 2001.

16. Gayotto LCC. Biópsia hepática. In: Gayotto LCC (ed) Doenças do Fígado e Vias Biliares. Editora Atheneu, São Paulo, p.151-163, 2001.

17. Lee WM. Hepatitis B virus infection. New England Journal of Medicine 337:1733-1745, 1997

18. Luo KX, Zhou R, He C, Liang ZS, Jiang SB. Hepatitis B virus DNA in sera of virus carriers positive exclusively for antibodies to the hepatitis B core antigen. Journal of Medical Virology 35:55-59, 1991. 
19. Medrano FJ, Sánchez-Quijano A, Pineda J, Lissen E. Isolated anti-HBc and hepatitis B virus occult infection. Vox Sanguinis 61:140, 1991.

20. Minuk GY, Sun DF, Uhanova J, Zhang M, Caouette S, Nicolle LE, Gutkin A, Doucette K, Martin B, Giulivi A. "Occult hepatitis B virus infection in a North American community-based population”. Journal of Hepatology 42:480-485, 2005.

21. Nalpas B, Pourcel C, Feldmann G, Housset G, Tiollais P, Brechot C, Berthelot P, Farza H. Chronic alcohol intoxication decreases the serum level of hepatitis $B$ surface antigen in transgenic mice. Journal of Hepatology 15:118-124, 1992.

22. Paterlini P, Poussin K, Kew M, Franco D, Brechot C. Selective accumulation of the $\mathrm{X}$ transcript of hepatitis B virus in patients negative for hepatitis B surface antigen with hepatocellular carcinoma. Hepatology 21:313-321, 1995.

23. Piliero PJ, Faragon JJ. Case report. Hepatitis B virus and HIV coinfection. AIDS Read 12:443-444, 2002.

24. Raimondo G. Occult hepatitis B virus infection and liver disease: fact or fiction?. Journal of Hepatology 34:471-473, 2001.

25. Sherlock S, Dooley J. Características Gerais das Hepatites crônicas e Hepatite crônica Auto-imune. $I n$ : Sherlock S, Dooley J (eds) Doenças do Fígado e do Sistema Biliar, $11^{\mathrm{a}}$ edição, Guanabara Koogan, Rio de Janeiro, p. $277-288,2004$.
26. Thiers V, Nakajima E, Kremsdorf D, Mack D, Schellekens H, Driss F, Goudeau A, Wands J, Sninsky J, Tiollais P. Transmission of hepatitis B seronegative subjects. Lancet 2:1273-1276, 1988.

27. Torbenson M, Thomas DL. Occult hepatitis B. The Lancet infectious Diseases 2:479-486, 2002.

28. Weber B, Muhlbacher A, Melchior W. Detection of an acute asymptomatic HBSAg negative hepatitis B virus infection in a blood donor by HBV DNA testing. Journal of Clinical Virology 32:67-70, 2005.

29. Weinberger KM, Bauer T, Bohm S, Jilg W. High genetic variability of the group specific a-determinant of hepatitis B virus surface antigen (HBsAg) and the corresponding fragment of the viral polymerase in chronic virus carriers lacking detectable HBsAg in serum. The Journal of General Virology 81:1165-1174, 2000.

30. Zhang YY, Hansson BG, Kuo LS, Widell A, Nordenfelt E. Hepatitis B virus DNA in Serum and Liver Is Commonly Found in Chinese Patients with Chronic Liver Disease Despite the Presence of Antibodies to HBsAg. Hepatology 17:538-544, 1993.

31. Zuckerman JN, Zuckerman AJ. Mutations of the surface protein of B virus. Antiviral Research 60:75-78, 2003. 